\title{
Lithium Disilicate Crown, Zirconia Hybrid Abutment and Platform Switching to Improve the Esthetics in Anterior Region: A Case Report
}

This article was published in the following Dove Press journal: Clinical, Cosmetic and Investigational Dentistry

\author{
Dario Adolfi ${ }^{\prime}$ \\ João Paulo Mendes Tribst $(\mathbb{D})^{\prime}$ \\ Maurício Adolfi iD ${ }^{2}$ \\ Amanda Maria de Oliveira \\ Dal Piva (iD) \\ Guilherme de Siqueira \\ Ferreira Anzaloni Saavedra (D) \\ Marco Antonio Bottino (D) ${ }^{\prime}$ \\ 'Department of Dental Materials and \\ Prosthodontics, São Paulo State \\ University (Unesp), Institute of Science \\ and Technology, São José dos Campos, \\ São Paulo, Brazil; ${ }^{2}$ Private Practice, São \\ Paulo, Brazil
}

\begin{abstract}
The hybrid abutment emerged as an alternative to maintain a stable and favorable volume of peri-implant tissue; it is composed of a mesostructure in ceramic and a metallic connection, which can be machined according to the peri-implant emergence profile. This case report presented the clinical steps for a dental implant with immediate provisional restoration, followed by the installation of implant-supported all-ceramic crowns with zirconia abutment and platform switching. A 40-year-old male patient was rehabilitated with an implant-supported ceramic crown in the region of element 11 and a ceramic veneer was cemented on the upper right central incisor. To do so, an atraumatic extraction of the upper left central incisor was performed followed by implant placement and immediate loading. In this case, a zirconia hybrid abutment was used with a metallic link in the cervical region with a concave platform switching base. This association of clinical steps enabled improving the aesthetics in the anterior dental region.
\end{abstract}

Keywords: dental implants, soft tissue, esthetic, adhesive

\section{Introduction}

Rehabilitation with osseointegrated dental implants is a well-documented modality in the literature for patients with the need for partial or full-arch prostheses. ${ }^{1}$ However, a dental implant therapy in the aesthetic area is undoubtedly one of the most challenging procedures among current dental rehabilitations. ${ }^{2}$

The difficulty in achieving a balance between a long-term success restoration and the patient's aesthetic expectations results in selecting glass and polycrystalline ceramic materials for the restoration. ${ }^{2-4}$ As with minimally traumatic extraction surgeries to preserve hard and soft tissues, the aim is to ensure an adequate implant installation with the possibility of immediate loading in the same surgical procedure. $^{5}$

Immediate loading ensures fewer clinical and laboratory procedures, allows soft tissue modeling during healing, and facilitates case prognosis. ${ }^{2}$ In addition, the use of platform switching abutments can maintain even more soft tissue around the implant, with adequate chewing load distribution and acceptable strength. ${ }^{6}$

As an alternative option to maintain a stable and favorable volume of periimplant tissue through immediate loading and concave abutments, the clinician may use a hybrid abutment composed of a ceramic mesostructure and a metallic link to improve the aesthethics. ${ }^{4}$ A hybrid abutment seeks to maintain the largest volume
Correspondence: João Paulo Mendes Tribst

Eng. Francisco José Longo, $\mathrm{n}^{\circ}$ 777. Jardim São Dimas, São José dos Campos 12245 000, SP, Brazil

Tel +55 I2 39479032

Fax +551239479010

Email joao.tribst@gmail.com 
of its structure in ceramic and the connection in metal, which can be machined according to the peri-implant emergence profile. $^{7-9}$

The literature has not yet reported how the association of all these methods can be performed in a single case, nor how the final result can be harmonically presented between soft, hard and synthetic materials. Therefore, the purpose of this case report was to present the clinical steps for a dental implant with immediate provisional restoration, followed by implant-supported all-ceramic crowns with zirconia abutment and platform switching. The patient provided written informed consent for publication of his data and photos.

\section{Case Report}

A 40-year-old male patient was referred to the dental office with a complaint of smile dissatisfaction relating to the appearance of their maxillary incisors associated with pain during chewing. Figures 1 and 2 present the initial case showing extensive restoration in the anterior teeth and color mismatch of the incisors. The clinical examination revealed extensive direct restorations in the anterior teeth with unsatisfactory color and unusual movement of the crown. Unsatisfying endodontic treatment was detected during the radiographic examination, and radicular fracture in the cervical area with signs of initial periodontal injuries. The patient was provided with complete information regarding treatment options to make a decision before tooth extraction, with implant placement in \#11 and manufacturing of a ceramic veneer for element \#21.

\section{Atraumatic Extraction and Immediate Implant Placement}

Cone-beam computed tomography (CBCT) image for the patient displayed sufficient alveolar bone support around element \#11. The tooth crown was secured extraorally using a forceps (Figure 3A) and removed (Figure 3B). The root canal was shaped and enlarged (Figure 3C) using Gates-Glidden

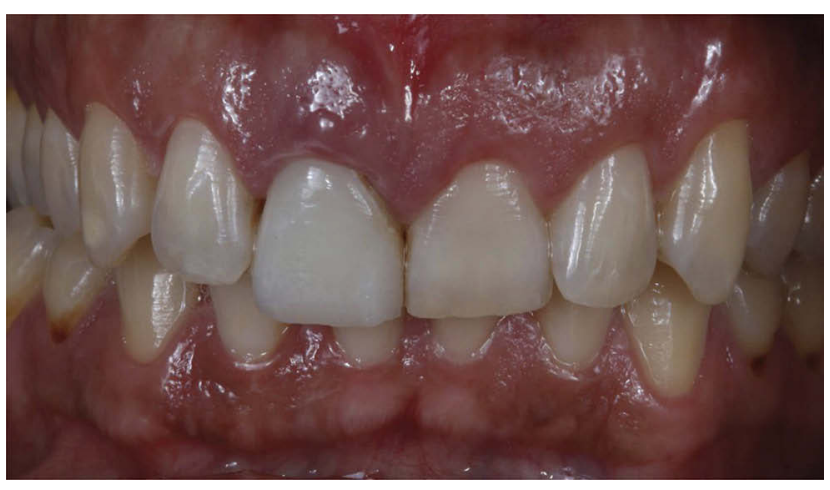

Figure 2 Initial case showing extensive restoration in the anterior teeth and color mismatch of the central incisors. It is possible to note the periodontal inflammation in the region of the element II.

drills. A diamond bur was used to prepare an access cavity for insertion of a self-tapping anchor screw (diameter $=1.8 \mathrm{~mm}$ ) into the coronal part of the root. The root extractor (Apex Control, Meisinger USA. L.L.C.) was assembled and placed on the adjacent teeth (lateral incisive and central incisive) (Figure 3D). Next, a pull string was attached to the anchor screw and the tooth was extruded gradually by increasing the tensile force without lateral movements (Figure $3 \mathrm{E}$ ). Figure $3 \mathrm{~F}$ presents the occlusal view of the alveolus.

An internal connection implant (Galimplant, Dental Implant System, Lugo, Spain) was selected for this case with $3.5 \mathrm{~mm}$ diameter and $12 \mathrm{~mm}$ length. The implant was placed at $2 \mathrm{~mm}$ above the level of the buccal plate of the crestal bone. The installation torque of the implant was ensured at $40 \mathrm{~N} . \mathrm{cm}$, and a transepithelial abutment (Galimplant, Dental Implant System, Lugo, Spain) was installed with 30 N.Cm on the implant. Figure $4 \mathrm{~A}-\mathrm{F}$ summarizes the implant installation. The buccal gap was filled with an allergen-free bone substitute material of bovine origin (Bio-Oss, Geistrich, Swiss).

\section{Temporary Restoration}

After implant placement (Figure 4A-D), an implant temporary framework (Immediate load Abutment, Galimplant, Dental Implant System, Lugo, Spain) made in PEEK

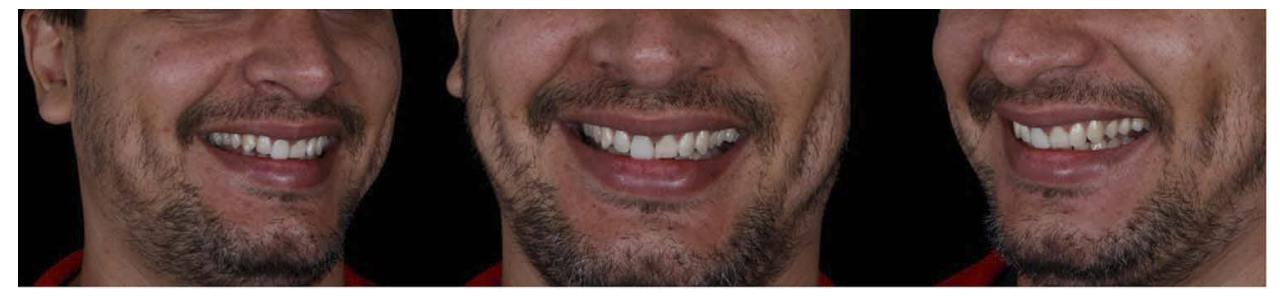

Figure I Initial smile showing the compromised aesthetics of the superior central incisors. 


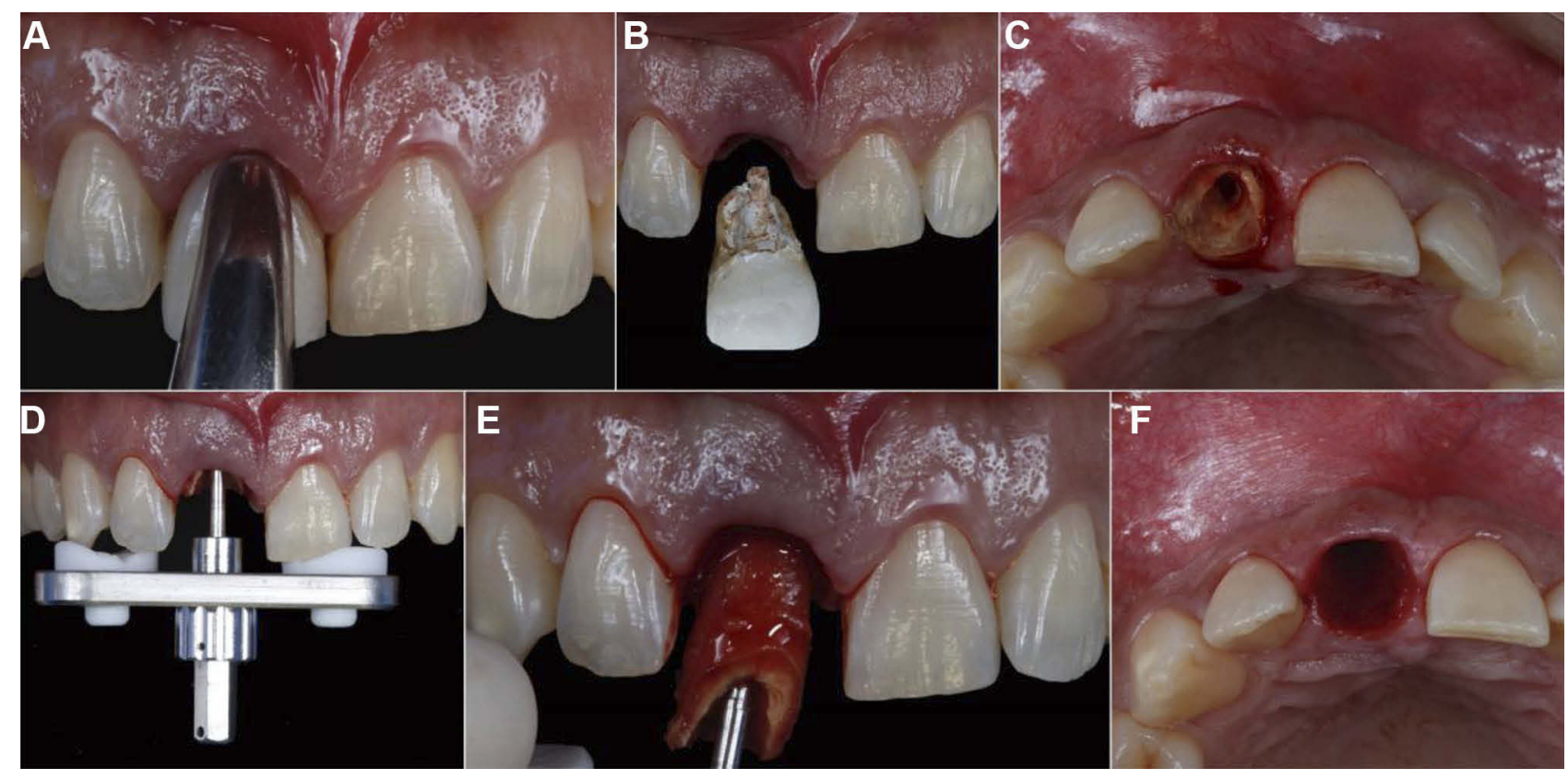

Figure 3 (A-F) Atraumatic surgical procedure. (A, B) fractured crown removal, (C) root prepared for the positioning of the extractor device. (D) Frontal view of the positioned device. (E) Root extraction and $(\mathbf{F})$ the final aspect of the surgical alveolus with soft and hard tissue preservation.

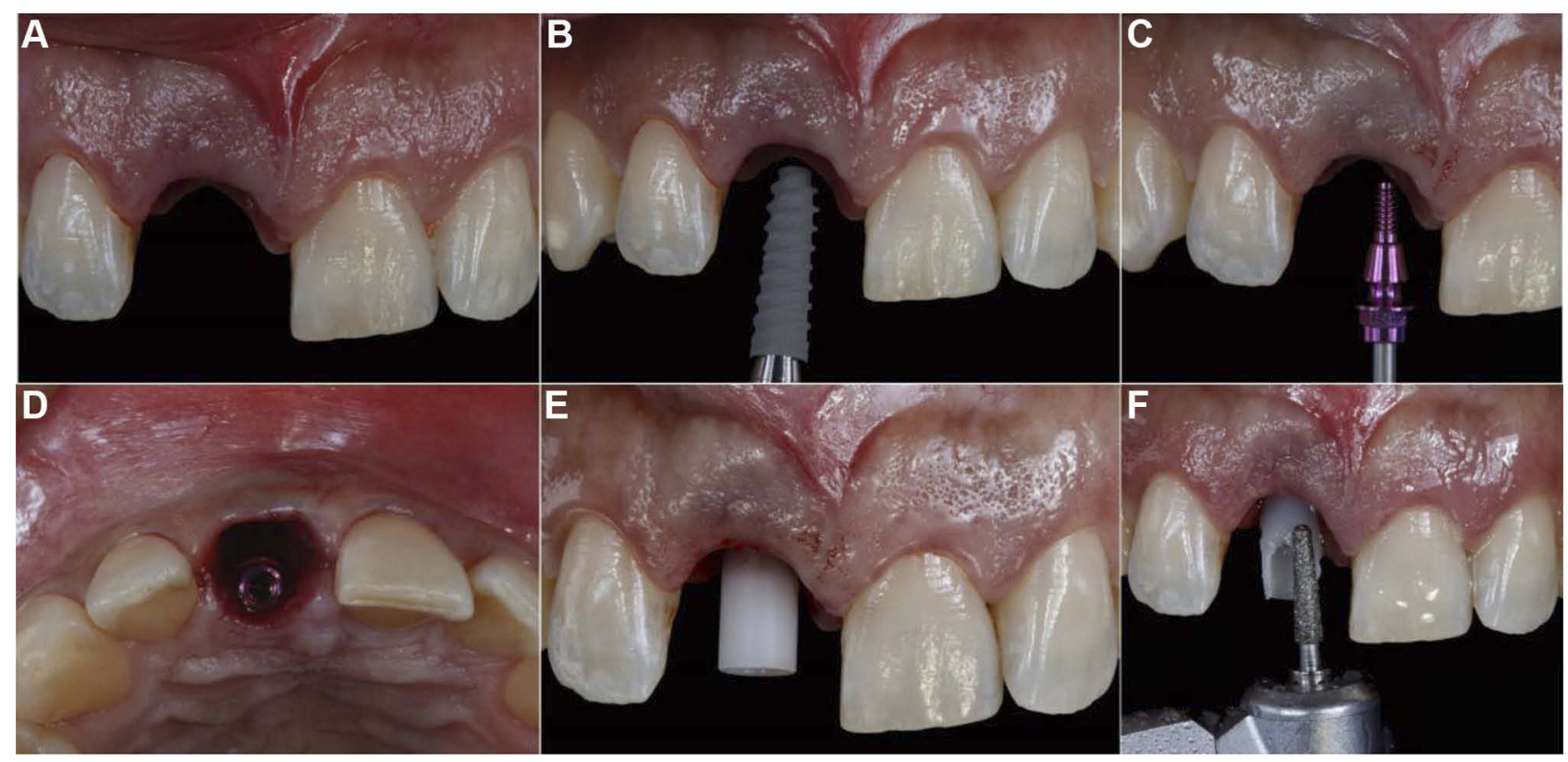

Figure 4 (A-F) Implant placement procedure and temporary abutment preparation. (A) Frontal view of the alveolus. (B) Implant installation. (C, D) Abutment installation. (E) Implant temporary framework installation and $(\mathbf{F})$ adaptation.

(Polyetheretherketone) was used (Figure 4E). The framework was connected with a manual torque wrench to the implant in the patient's mouth, and Teflon tape was used to fill the screw access hole. Next, the cylinder was individualized with a diamond-bur (\#2136) and constant water source as a conventional preparation for cemented crown (Figure 4F). After the protection of the access hole with
Teflon tape (Figure 5A and B), a temporary prefabricated crown (Premium, Heraeus Kulzer, Hanau, Germany) was selected with approximately the same dimensions of the adjacent tooth and color. The crown was adapted using a tungsten bur and positioned with acrylic resin in contact with the temporary abutment (Figure 5C). After the resin polymerization, the set was gently removed from the 


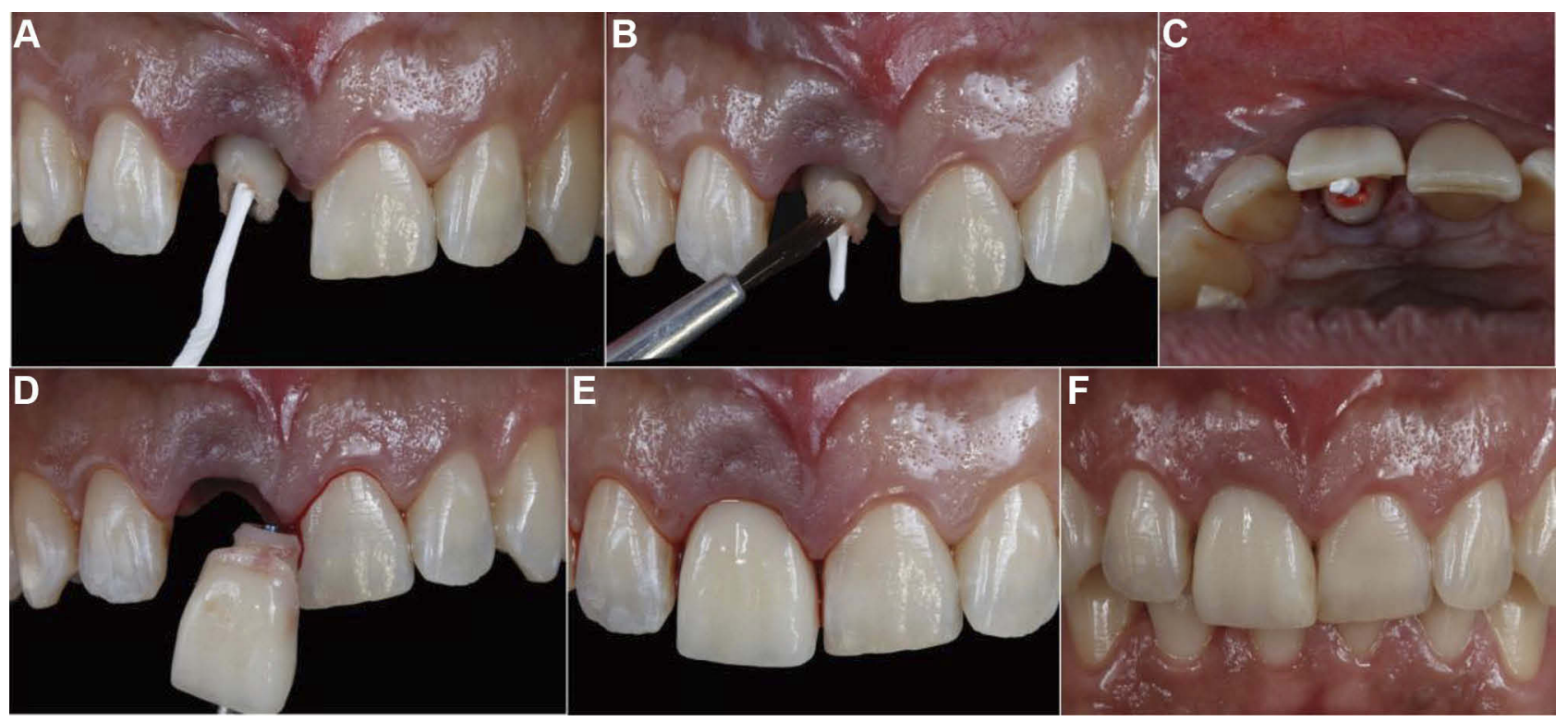

Figure 5 (A-F) Temporary crown individualization. (A) A Teflon tape was used to protect the screw access hole. (B, C) Insertion of acrylic resin at the abutment's anterior face, and, the positioning of the individualized veneer. (D) Removal of the unfinished temporary crown. (E, F) The crown in position immediately and after the healing period.

abutment and the final shape was manually performed with acrylic resin (Figure 5D). After the shaping, the temporary crown was polished with diamond rubbers (Astropol, Ivoclar Vivadent, Schaan, Liechtenstein) and a layer of acrylic glaze (Palaseal, Kulzer, São Paulo, Brazil) was applied on its surface. The crown was installed with a manual torque wrench, the prosthetic screw was protected with Teflon tape, and the buccal access hole was sealed with acrylic resin. Figure 5E and $\mathrm{F}$ present the provisional restoration in position. Post-operative instructions were given to the patient and recall visits were done after 7 days, 4 weeks, 8 weeks and 12 weeks. The healing was assessed on each follow-up appointment with no signs of inflammation or infection. In addition, the development of the soft tissue emergence profile around the implant was monitored and the provisional restoration was adjusted when required. Aesthetics and phonetics were evaluated and the patient displayed complete satisfaction with the outcome.

\section{Zirconia Abutment Manufacturing}

After the healing period (90 days), an open tray impression was done using polyvinylsiloxane impression materials (Virtual, Ivoclar Vivadent, Schaan, Liechtenstein). The transference of the emergence profile of the soft tissue was performed with the temporary crown, removing the prosthethic screw prior to the impression (Figure 6A). The analogous implant was subsequently connected with the abutment and the artificial peri-implant soft tissue created with soft material (Gingifast, Zhermack, Italy) (Figure 6B). The stone model was manufactured in gypsum type IV with low expansion (GC FujiRock EP, type 4 dental stone, GC Europe, Leuven, Belgium). Next, the emergence profile and the cervical contour were checked and approved by the dentist and technician (Figure 6C and D).

The zirconia mesostructure (Ceramill Zolid; Amann Girrbach, Paraná, Brazil) was milled in a machining unit (Ceramil Motion II, Amann Girrbach, Paraná, Brazil). The zirconia was initially present in the monoclinic phase, $20 \%$ higher in volume than the final shape (Figure 7). The sintering process was carried out in a ceramic oven (Infire HTC speed, Sirona) according to the manufacturer's instructions. A metallic link was used for the connection between the zirconia mesostructure and the abutment (Figure 7). The link received a surface treatment with aluminum oxide $50 \mu \mathrm{m}$ blasting with $2.0 \mathrm{bar}$; it was then cleaned in an ultrasonic bath for $5 \mathrm{~min}$. The link was dried with an air jet and received a layer of a primer for metal (Alloy Primer, Kuraray Noritake Dental Inc.; Tokyo, Japan). The zirconia intaglio surface received a layer of Ceramic Primer (Clearfil Ceramic Primer, Kuraray Noritake Dental Inc.; Tokyo, Japan). The zirconia mesostructure and the metallic link were cemented with the dual resin cement (Panavia F 2.0 Kuraray Noritake Dental Inc.; Tokyo, Japan) and each face of the set received light activation for $20 \mathrm{~s}$ (Valo, Ultradent Products Inc, South Jordan, 


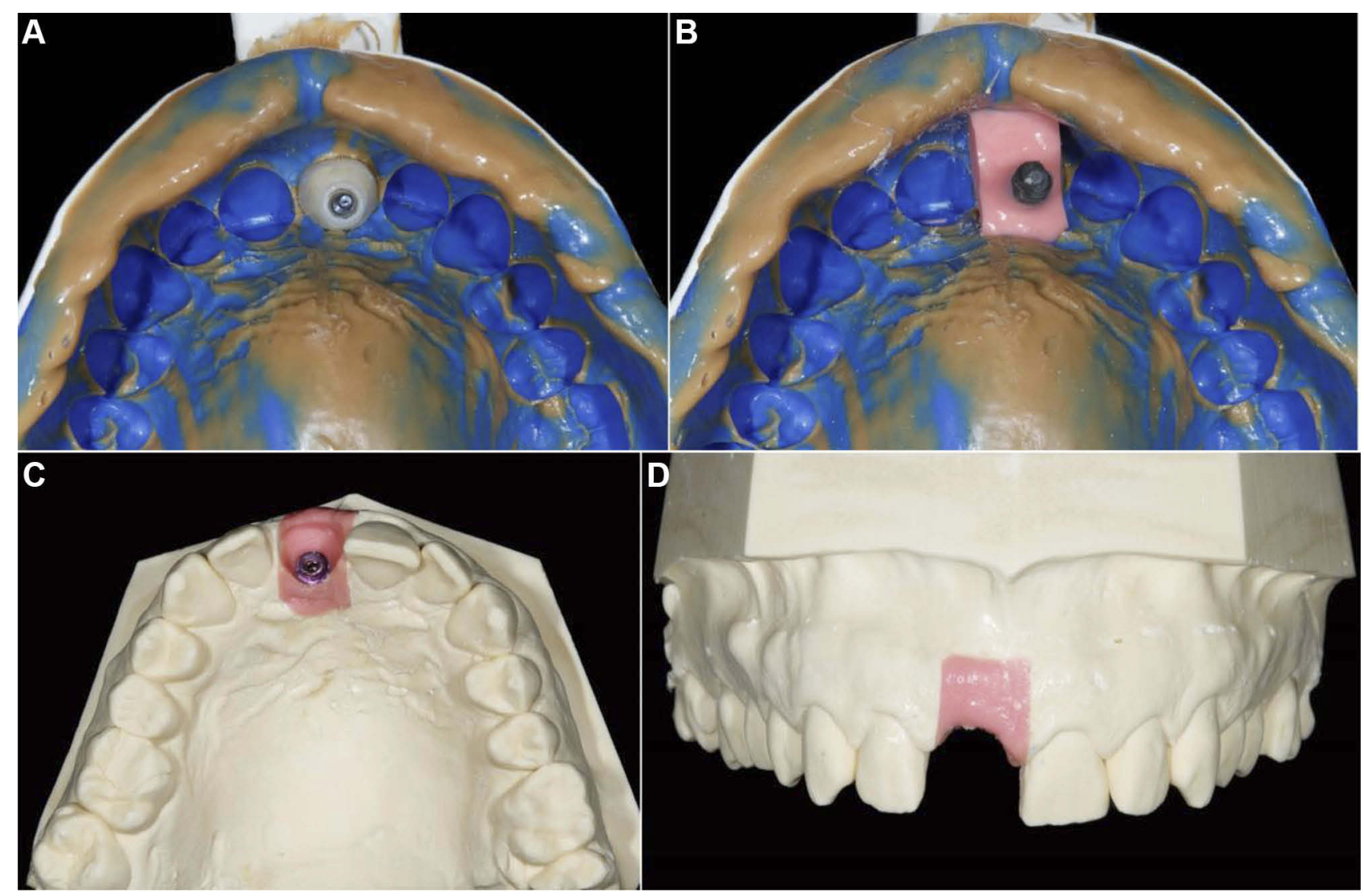

Figure 6 (A-D) (A, B) Impression with the transferred temporary crown. (B) Artificial peri-implant soft tissue. (C, D) Stone model with adequate emergence profile and implant soft-tissue contours.

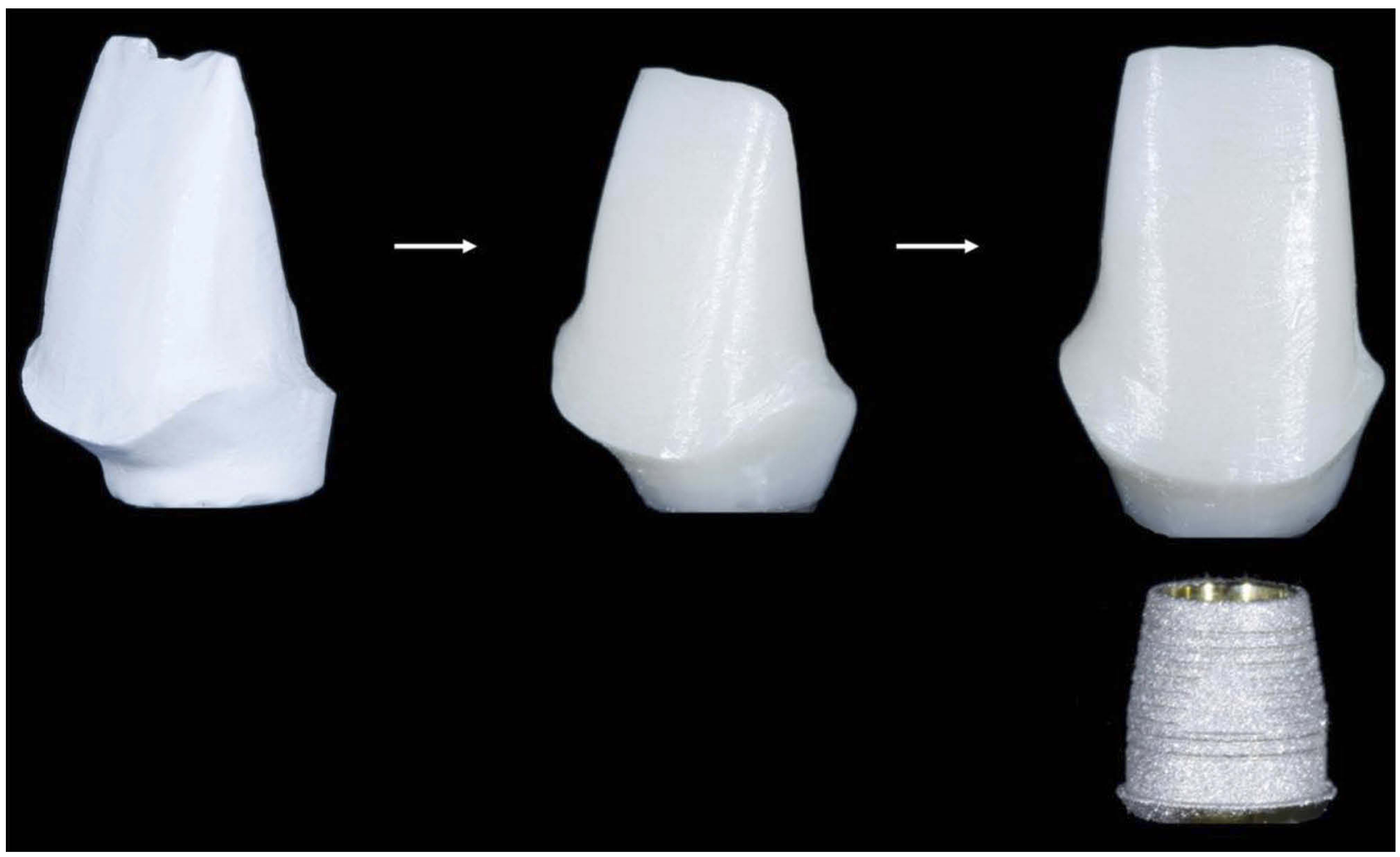

Figure 7 Zirconia mesostructure immediately after machining, after sintering process and with the metallic link. 
UT, USA). After the complete polymerization of the resin cement, the occlusal portion of the zirconia preparation was sandblasted with aluminum oxide $50 \mu \mathrm{m}$ under 2.0 bar. This set was installed with 30 N.cm (Figure 8A-C). The screw access hole was protected with Teflon tape and then filled with composite resin (IPS Empress Direct, Ivoclar Vivadent, Schaan, Liechtenstein).

\section{Ceramic Restorations}

Lithium disilicate based ceramic with high translucency was selected to manufacture both implant-supported crowns and veneers. For the veneer preparation, a retraction cord size \#00 (Ultradent, Products Inc, South Jordan, UT, USA) was placed inside the sulcus for mechanical retraction (Figure 8D). Then, the preparation followed the feather design with incisal edge involvement. An open tray was performed with polyvinylsiloxane impression materials (Virtual, Ivoclar Vivadent, Schaan, Liechtenstein) and a stone model was created (GC FujiRock EP, type 4 dental stone, GC Europe, Leuven, Belgium). The crown and the veneer (IPS e.max CAD HT A1, Ivoclar Vivadent, Schaan, Liechtenstein) were milled (Ceramil Motion II, Amann Girrbach, Paraná, Brazil) and crystallized in a ceramic oven (Programat P700; Ivoclar Vivadent, Schaan, Liechtenstein) according to the manufacturer's instructions. The crown then received and extrinsic shade characterization with ceramic stain (IPS e.max ceram, Ivoclar) (Figure 9).

Absolute isolation for the adhesive cementation procedure was performed with a rubber dam and an implant transfer was positioned with flow composite resin to avoid debris in the implant (Figure 10A). The vital tooth received a surface treatment of total etching (Phosphoric acid 35\%, Ultra-Etch, Ultradent, Products Inc, South Jordan, UT, USA) for $30 \mathrm{~s}$ (Figure 10B), and then it was washed, dried and received a layer of multimode adhesive (Adper Single Bond, 3M ESPE, Dental Products, Minnesota, USA) (Figure 10C). The ceramic veneer inner surface was etched with hydrofluoric acid for $20 \mathrm{~s}$, washed and dried. The adhesive cement (Panavia F 2.0 Kuraray Noritake Dental Inc.; Tokyo, Japan) was manipulated according to the manufacturer's recommendations and the veneer was cemented
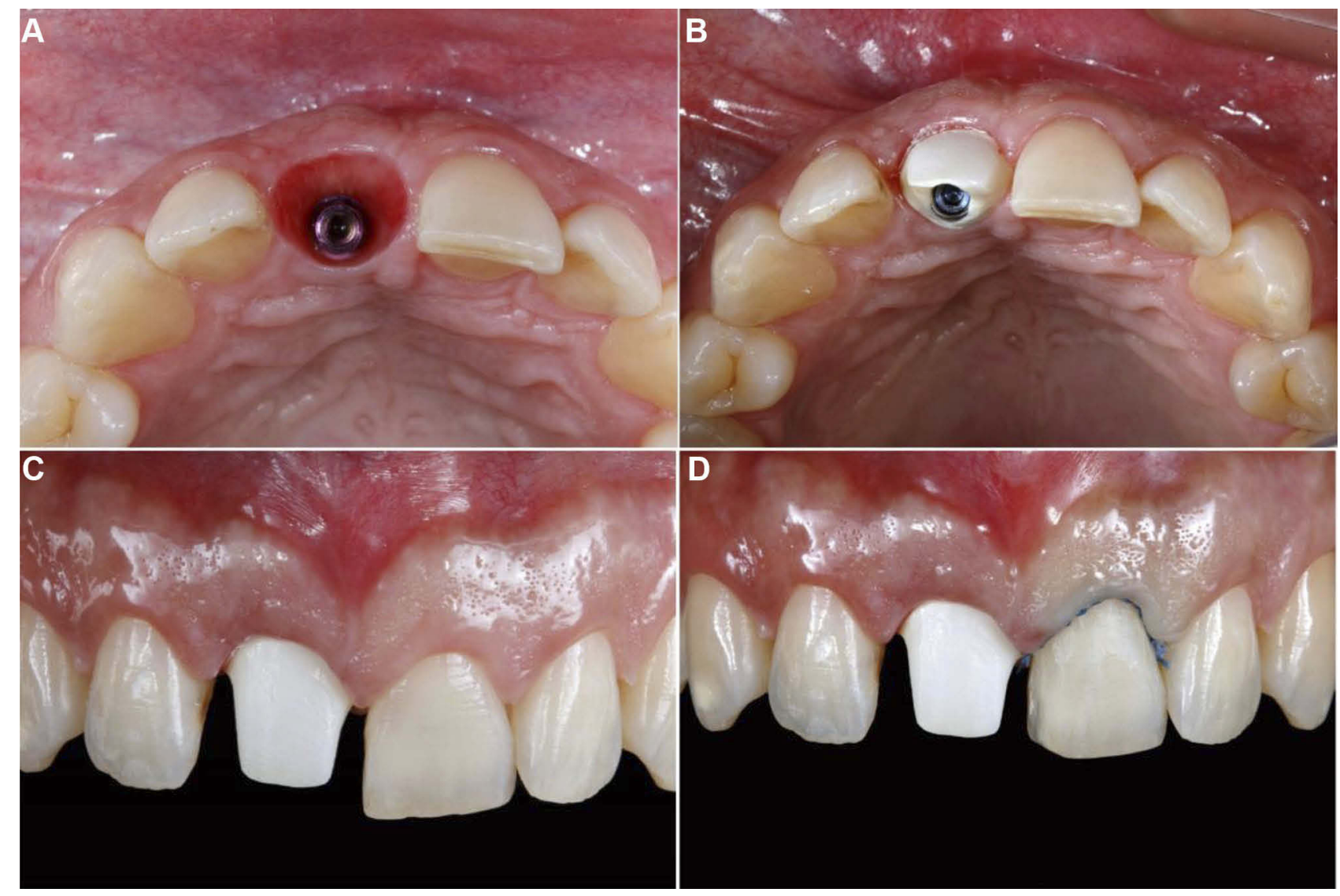

Figure 8 (A-D) (A) Soft tissue aspect after temporary crown removal. (B, C) installation of the hybrid abutment in position. (D) Preparartion of the element 2 I for the ceramic veneer. 


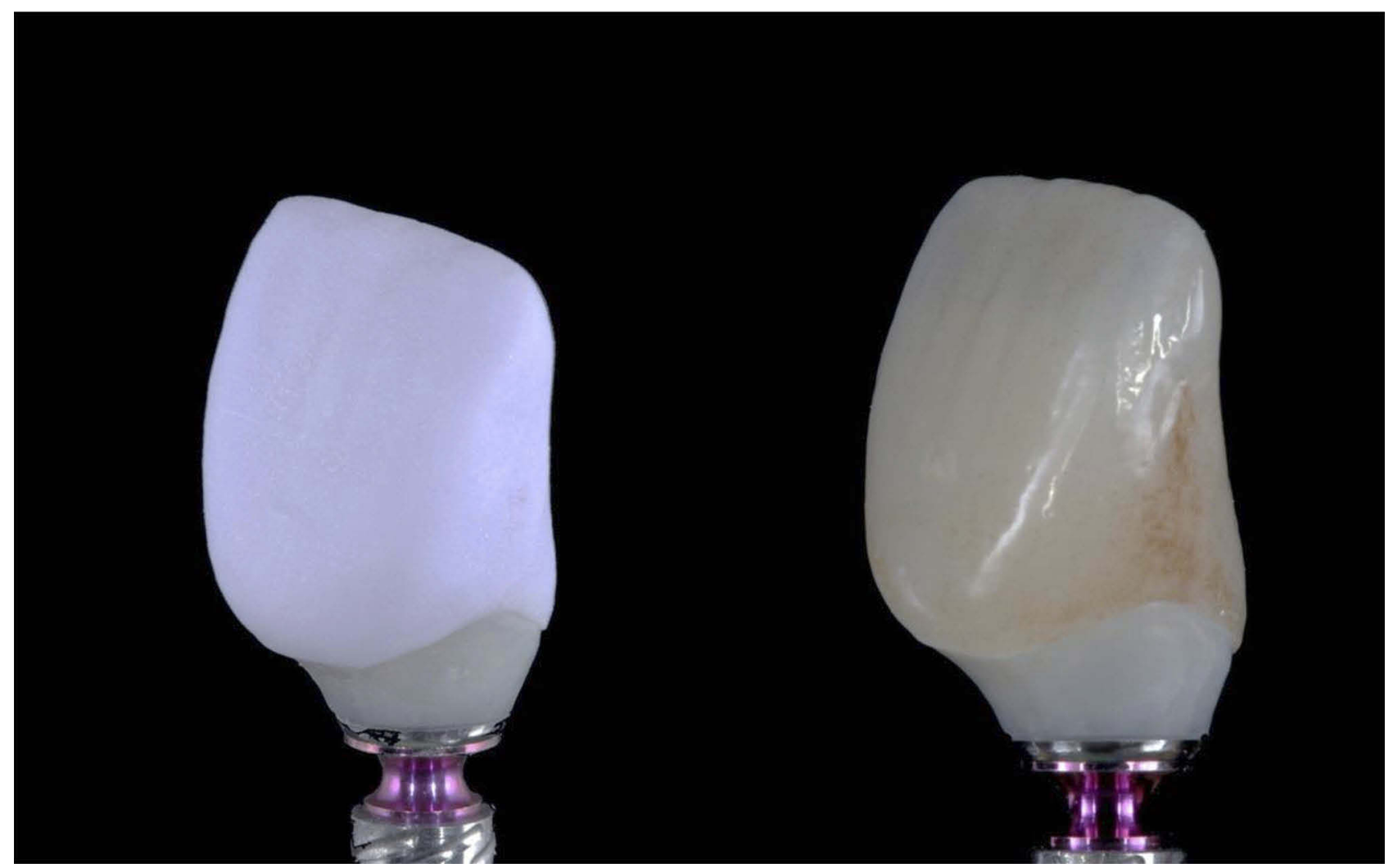

Figure 9 Comparison between the lithium disilicate crown after the crystallization firing and after the shade characterization. Note the platform switching at the abutment profile.

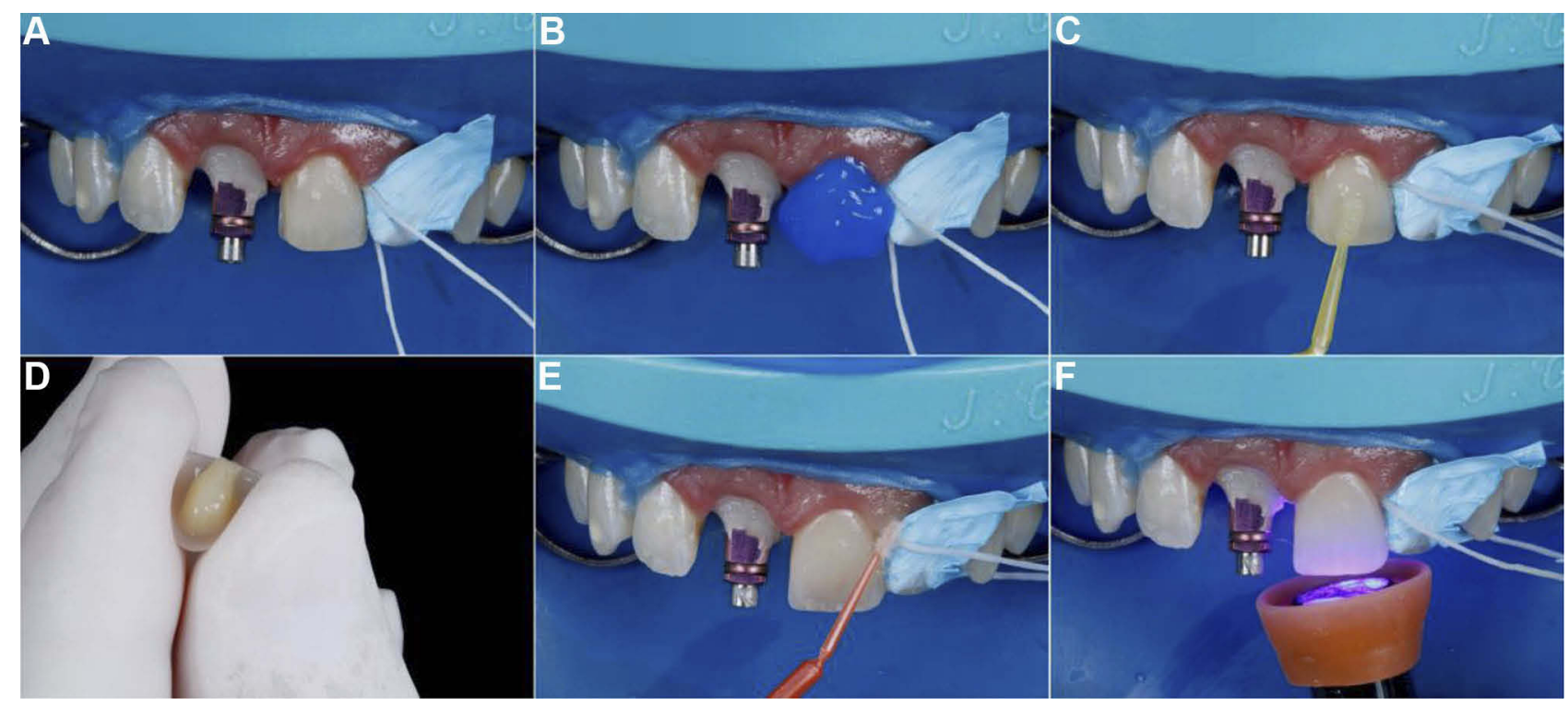

Figure 10 (A-F) Ceramic veneering adhesive cementation. (A) Tooth prepared to receive a veneer and the implant protection with an individualized transfer. (B) Tooth substrate acid etching. (C) Adhesive system application. (D) Resin cement application on the ceramic veneer intagliosurface. (E) Excess cement removal with a microbrush. (F) Light activation.

(Figure 10D). The excess resin cement was removed (Figure 10E) and photoactivation was then performed (Figure 10F).
For the implant-supported crown, the analogous was removed, the set installed with 30 N.cm, the screw access hole was protected with Teflon tape (Figure 11A and B) 

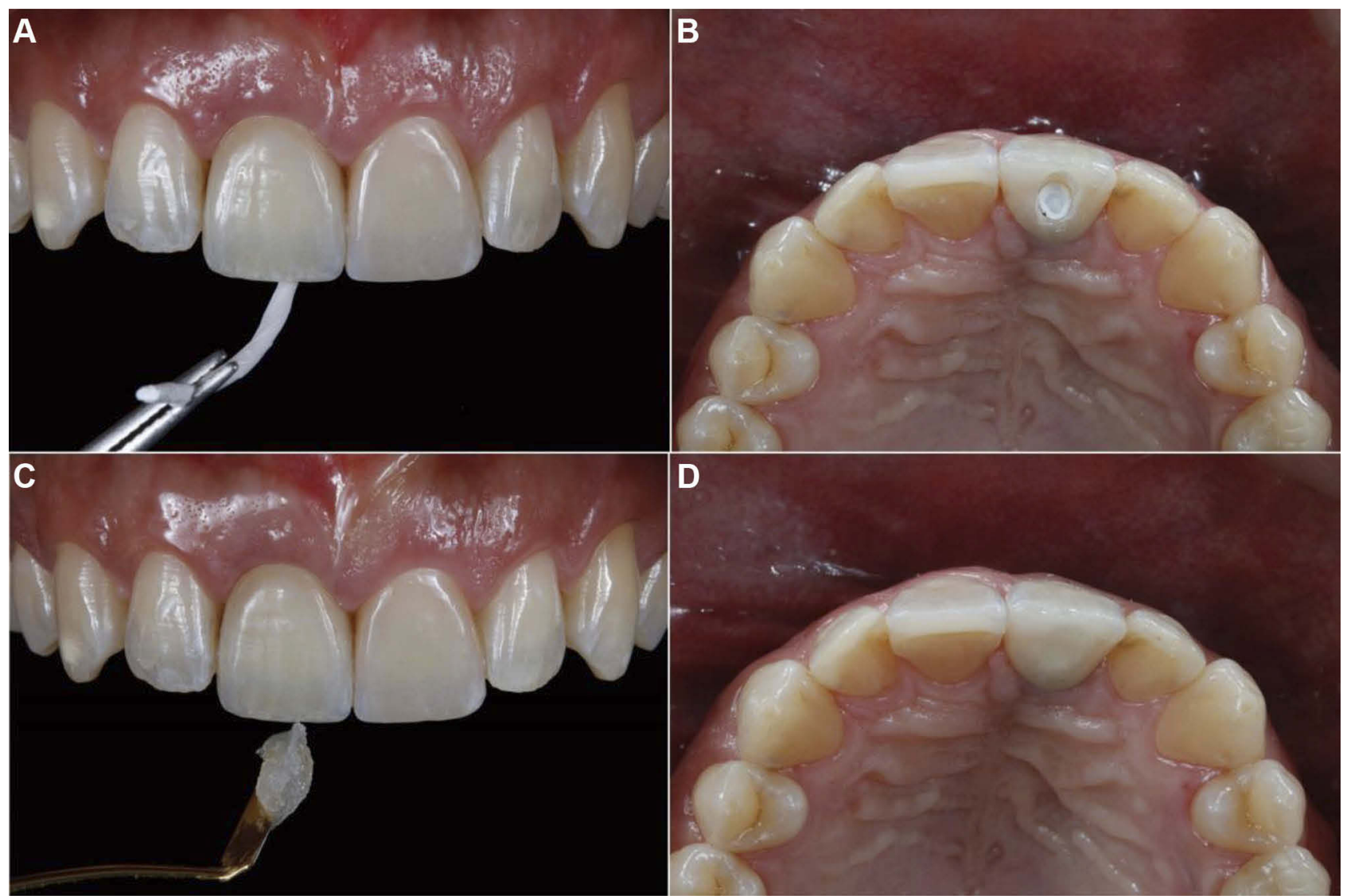

Figure I I (A-D) (A, B) Screw protection with a Teflon tape. (C, D) Screw access hole sealing with composite resin.

and it was then sealed with composite resin (Figure 11C and D).

The recall visits were done after 2 weeks, 3 months, and 6 months counting from the delivery of the ceramic restorations (Figure 12). The patient reported being satisfied with the aesthetics and functional outcome of the ceramic restorations.

\section{Discussion}

Dental implant rehabilitation can be defined as successful when the natural contours of the lost element are recovered in the prosthesis, achieving harmony with the adjacent teeth. ${ }^{1-3}$ The final result of the presented clinical case demonstrated the importance of an atraumatic extraction to preserve the supporting bone tissue and to maintain a large and natural-looking for the peri-implant soft tissue. ${ }^{5}$ Immediate loading by the installation of a well-defined temporary crown with a concave and wellpolished emergence profile ensures better tissue resilience after surgery, with almost no unwanted remodeling, which in turn facilitates the prognosis of the case. ${ }^{10}$ However, it is important that this emergence profile

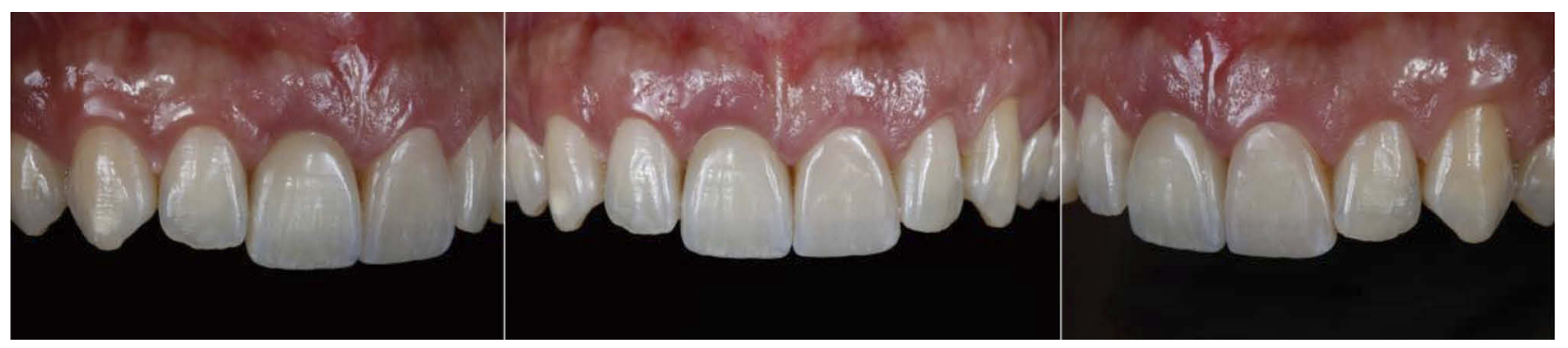

Figure 12 Final smile showing the achieved aesthetics and soft tissue health. 
achieved with the temporary crown during healing is also transferred to the model for manufacturing the final restoration, thereby enabling anatomic similarity of both temporary and final crowns.

The use of a concave abutment for the switching platform also increases the amount of soft tissue in the region and promotes satisfactory aesthetics, even during temporary crown installation. ${ }^{6}$ The zirconia mesostructure metal link is used to ensure a hybrid abutment with a large amount of polycrystalline material which diminished the grayish effect on the mucosa; ${ }^{4}$ however, it also ensures the metallic connection between abutment and crown at the same time, which reduces the incidence of mechanical problems in this interface. ${ }^{9}$

For this case, the veneering manufacture on the adjacent tooth made in the same material as the implant-supported crown helped to achieve a final harmonic smile. However, this restorative modality should only be performed when the healthy tooth has the indication for it, as in this case. ${ }^{11,12}$ Specifically for this case, the treatment in the anterior region presented a much more favorable prognosis due to the higher levels of bone due to the altered passive eruption. As a study`s limitations the radiographs are not available.

The lithium disilicate ceramic material was selected because it is a reliable material with a glass matrix reinforced by the disilicate crystals which decreases the crack propagation in these restorations, and also because it can generate aesthetics and adequate resistance to chewing loads. $^{13}$ It is also important to emphasize the need to perform an adequate adhesive procedure with isolation of the operative field using a rubber dam, thereby avoiding saliva residue in the dental substrate. ${ }^{14}$ Adequate acid etching in the restoration is also important for the glass matrix to be dissolved and to ensure adequate and durable adhesive bond strength between the restoration and resin cement. $^{15}$

\section{Conclusion}

The use of a crown in lithium disilicate cemented onto a zirconia hybrid abutment with platform switching enabled improving the aesthetics in the anterior dental region. This is a case report and further studies are needed with followup intervals of longer duration to confirm the proposed treatment.

\section{Disclosure}

The authors report no conflicts of interest in this work.

\section{References}

1. Romanos GE, Delgado-Ruiz R, Sculean A. Concepts for prevention of complications in implant therapy. Periodontol 2000. 2019;81(1):717. doi: $10.1111 /$ prd.12278

2. Qutub OA, Basunbul GI, Binmahfooz AM. Influence of abutment material on the shade of dental implant restorations in the esthetic zone: a single case report. Clin Cosmet Investig Dent. 2019;2019 (11):73-80. doi:10.2147/CCIDE.S199635

3. Barreto JO, Albuquerque IS, Alencar-Silva F, Pinto-Fiamengui LMS, Regis RR. Combining different ceramic systems and periodontal microsurgery in maxillary esthetic areas: a case report. Gen Dent. 2019;67(5):68-71.

4. Tribst JPM, Dal Piva AMO, Borges ALS, Bottino MA. Different combinations of CAD/CAM materials on the biomechanical behavior of a two-piece prosthetic solution. Int J Comput Dent. 2019;22 (2):171-176.

5. Kelly RD, Addison O, Tomson PL, Krastl G, Dietrich T. Atraumatic surgical extrusion to improve tooth restorability: a clinical report. $J$ Prosthet Dent. 2016;115(6):649-653. doi:10.1016/j.prosdent.2015. 09.028

6. Pan YH, Lin HK, Lin JC, et al. Evaluation of the peri-implant bone level around platform-switched dental implants: a retrospective 3year radiographic study. Int J Environ Res Public Health. 2019;16 (14):2570. doi:10.3390/ijerph16142570

7. Tribst JPM, Piva AMDOD, Borges ALS, Bottino MA. Influence of crown and hybrid abutment ceramic materials on the stress distribution of implant-supported prosthesis. Rev Odontol UNESP. 2018;47 (3):149-154. doi:10.1590/1807-2577.04218

8. Tribst JPM, Dal Piva AMO, Özcan M, Borges ALS, Bottino MA. Influence of ceramic materials on biomechanical behavior of implant supported fixed prosthesis with hybrid abutment. Eur J Prosthodont Restor Dent. 2019;27(2):76-82. doi:10.1922/EJPRD_01829Tribst07

9. Tribst JPM, Dal Piva AMO, Anami LC, Borges ALS, Bottino MA. Influence of implant connection on the stress distribution in restorations performed with hybrid abutments. J Osseointegration. 2019;11(3).

10. Doliveux S, Jamjoom FZ, Nadra M, Gallucci GO, Hamilton A. Fabrication technique for a custom implant emergence profile on 3D printed casts. J Prosthet Dent. 2019;S0022-3913(19):30274.

11. Stappert CF, Goldstein RE, Tjiptowidjojo FA, Chu SJ. Ceramic veneers and partial-coverage restorations. In: Ronald E, editor. Goldstein's Esthetics in Dentistry. London: Harcourt-Brace \& Company Ltd; 1998:432-497.

12. Costa VLS, Tribst JPM, Uemura ES, de Morais DC, Borges ALS. Influence of thickness and incisal extension of indirect veneers on the biomechanical behavior of maxillary canine teeth. Restor Dent Endod. 2018;43(4):e48. doi:10.5395/rde.2018.43.e48

13. Dal Piva AMO, Tribst JPM, Saavedra GSFA, et al. Short communication: influence of retainer configuration and loading direction on the stress distribution of lithium disilicate resin-bonded fixed dental prostheses: 3D finite element analysis. J Mech Behav Biomed Mater. 2019;100:103389. doi:10.1016/j.jmbbm.2019.103389

14. de Lourdes Rodrigues Accorinte M, Reis A, Dourado Loguercio A, Cavalcanti de Araújo V, Muench A. Influence of rubber dam isolation on human pulp responses after capping with calcium hydroxide and an adhesive system. Quintessence Int. 2006;37(3):205-212.

15. Veríssimo AH, Moura DMD, Tribst JPM, Araújo AMM, Leite FPP, Souza ROAE. Effect of hydrofluoric acid concentration and etching time on resin-bond strength to different glass ceramics. Braz Oral Res. 2019;33:e41. doi:10.1590/1807-3107bor-2019.vol33.0041 


\section{Publish your work in this journal}

Clinical, Cosmetic and Investigational Dentistry is an international, peer-reviewed, open access, online journal focusing on the latest clinical and experimental research in dentistry with specific emphasis on cosmetic interventions. Innovative developments in dental materials, techniques and devices that improve outcomes and patient satisfaction and preference will be highlighted. The manuscrip management system is completely online and includes a very quick and fair peer-review system, which is all easy to use. Visit http://www.dovepress.com/testimonials.php to read real quotes from published authors.

Submit your manuscript here: https://www.dovepress.com/clinical-cosmetic-and-investigational-dentistry-journal 